\title{
Comparative study of hermetic and non-hermetic storage on quality of cowpea in Ghana
}

\author{
Dominic Aboagye ${ }^{1}$, Joseph Ofei Darko ${ }^{2}$ and Noble Banadda ${ }^{{ }^{*}}$
}

\begin{abstract}
Background: Cowpea (Vigna unguiculata) serves as a major food and income generation crop for millions of people in sub-Saharan Africa and Central America. However, post-harvest losses associated with this crop still remain a critical issue of concern in most developing countries. This study was therefore carried out to investigate the effect of hermetic and non-hermetic storage on cowpea in plastic containers in the tropics. The cowpeas were stored in hermetic and non-hermetic containers over a period of 12 weeks. The parameters evaluated were the moisture content, insect infestation, usable proportion, and 1000 grain mass in both hermetic and non-hermetic systems.

Results: The moisture content in the hermetic containers increased slightly from 11.7 to $11.9 \%$ compared to a sharp increase from 11.7 to $17.2 \%$ in the non-hermetic plastic containers. From the fourth week to the twelfth week, the number of live insects drastically reduced to zero in the hermetic system. In the case of the non-hermetic containers, the population of live insects/100 $\mathrm{g}$ of grains increased from 5 on week $0-71$ on the twelfth week. Also, the mass of 1000 grains reduced from $156.50 \mathrm{~g}$ on week $0-145.21 \mathrm{~g}$ in the non-hermetically stored grains, while the hermetically stored grains recorded a decrease to $148.95 \mathrm{~g}$. Finally, the usable proportion of grains in the hermetic system declined from 98.55 to $94.80 \%$ after 12 weeks of storage as compared to the drop to $85.69 \%$ seen in the non-hermetic system.
\end{abstract}

Conclusions: Based on our findings, it was further concluded that hermetic storage could offer a better way of storing cowpea as compared to the non-hermetic system.

Keywords: Hermetic storage, Non-hermetic, Moisture content, Cowpea, Plastic containers, Insect

\section{Background}

Among the different leguminous grain crops present in Africa, cowpea still stands out as the most important crop which has high nutritional content and provides income for millions of poor farmers on the continent [1]. According to [2], cowpea provides food for over 200 million residents in Africa. It has been estimated that around $80 \%$ of the cowpea trade in the world is in West and Central Africa [1]. In effect, cowpea production has gone a long way to cut down the problem of hunger in most parts of Africa. However, post-harvest losses usually caused by cowpea bruchids remain a key problem for

\footnotetext{
*Correspondence: banadda@caes.mak.ac.ug

1 Department of Agricultural and Bio-Systems Engineering, Makerere

University, P.O. Box 7062, Kampala, Uganda

Full list of author information is available at the end of the article
}

many farmers $[1,3,4]$. The attack caused by cowpea weevil (Callosobruchus maculatus) has destroyed between 20 and 50\% cowpeas on the continent each year, and in certain areas this loss could be up to 100\% [5]. Losses in stored food products are highly prevalent in developing countries, especially among smallholder farmers. Among sub-Saharan African countries and other developing countries, these losses come as a result of inadequate use of highly improved post-harvest technologies during storage. Faced with such devastating losses, many farmers do not want to risk their cowpeas. Instead, they sell them at harvest time when prices are the lowest. Mapping up strategies to reduce these losses will ensure food security, lead to rapid economic growth, and improve nutrition on the continent $[6,7]$. 
With the emergence of simple post-harvest technologies, storage losses in cowpea can now be controlled without the use of pesticides. Many storage facilities have emerged, but sometimes are too expensive for many smallholder farmers in the tropics and sub-tropics to afford. Also, most of these farmers are not able to purchase pesticides to control pests and diseases during storage. Although the use of chemicals still remains a principal approach to solving post-harvest losses among many smallholder farmers, misuse of insecticides is common and causes health and environmental problems $[1$, 7]. The use of metal silos for storing grains, for instance, is only limited to the temperate regions. When used in hot, humid climates and semi-tropical regions, they produced negative results by causing humidity damage to the stored commodities [8]. It was further explained that during storage, grains experiencing too high temperature, adequate oxygen, and high relative humidity lead to the formation of molds which deteriorate grain quality. For most smallholder farmers in Africa, hermetic storage could be a practical approach because it is chemical-free and offers a cost-effective way of controlling insects during storage, thereby maintaining the quality of the grain [9-11]. Hermetic storage principally occurs in a controlled environment which continuously depletes oxygen and simultaneously increases carbon dioxide as a result of the respiratory activities of insects in the ecological system of a sealed storage [12]. According to [10], grain losses may vary depending on the geographical location, the year, the atmospheric condition, the available postharvest technologies, and finally the amount of grain harvested. Due to the many factors influencing the rate of grain deterioration, it is exceedingly difficult to quantify the losses in stored grain [13]. This work therefore took a major step to evaluate the effect of hermetic and nonhermetic storage on moisture content, insect infestation, grain mass, and usable proportion of grains obtained from a local farmer in Ghana.

\section{Materials}

A local variety of cowpea (locally called Soronko) was obtained from a local farmer in Kumasi, regional capital of the Ashanti region of Ghana. The region has a mean annual temperature of $32{ }^{\circ} \mathrm{C}$ and a mean monthly temperature ranging between $26^{\circ} \mathrm{C}$ in November and $27{ }^{\circ} \mathrm{C}$ in February. The average relative humidity for November, December, January, and February are $84,82,78$, and $75 \%$, respectively. In general, the experimental period fell within the months of November, December, January, and February. The storage and laboratory experiments took place at Animal Science Department of Kwame Nkrumah University of Science and Technology. Close to $50 \mathrm{~kg}$ of cowpea was poured onto a clean plane surface, mixed thoroughly, and foreign materials such as stones and broken grains were removed before the experiment was carried out. Seventy-eight transparent plastic containers with appropriate lids for storing the grains, an electronic oven for moisture content determination, an electronic balance, rectangular trays, muslin bags, polyethene rubbers, and mesh sieve of aperture size $4.80 \mathrm{~mm}$ were used to undertake this experiment.

\section{Experimental design}

The experiment was carried out under Completely Randomized Design (CRD) with two treatments and three replicates each. In all, 39 containers were used for hermetic storage and 39 used for the non-hermetic storage. The experiment was carried out for a period of 12 weeks. The hermetic containers were each filled with $500 \mathrm{~g}$ of grains, and six weevils were manually counted and placed into each. For each of the hermetic containers, polyethene rubbers were placed on them after which they were securely sealed with Teflon tape (also known as plumbing tape) prior to placing their lids to ensure airtight conditions as performed by [9]. The non-hermetic containers were also filled with $500 \mathrm{~g}$ of grains after which six weevils were manually counted and placed into each. Muslin cloth was placed on each of the non-hermetic containers to prevent the entry of other insects and also help air to circulate around the grains [12].

\section{Methods}

\section{Determination of moisture content of cowpea}

The oven method was used determine the moisture content of the cowpea. Each of the labeled trays was placed on the balance. In general, $100 \mathrm{~g}$ of grains was poured on a metallic tray and weighed using an electronic balance. The tray containing the grains was placed in an oven which was set at $103{ }^{\circ} \mathrm{C}$ for $24 \mathrm{~h}$, as performed in other studies $[9,14]$. After $24 \mathrm{~h}$, the trays were removed from the oven, and then the mass of the dried grains was determined. The moisture content readings were undertaken in triplicate for the hermetic and non-hermetic systems. The percentage moisture content by mass was computed using Eq. 1 which was also adopted by [4].

Moisture content (\% wet basis) $=\frac{\left(M_{\mathrm{i}}-M_{\mathrm{f}}\right)}{\left(M_{\mathrm{i}}-M_{\mathrm{t}}\right)} \times 100$,

where $M_{\mathrm{t}}=$ mass of empty tray $(\mathrm{g}), M_{\mathrm{i}}=$ mass of empty tray $(\mathrm{g})+$ mass of grain before drying $(\mathrm{g})$, and $M_{\mathrm{f}}=$ mass of empty tray $(\mathrm{g})+$ mass of grain after drying $(\mathrm{g})$.

\section{Determination usable proportion}

As recommended by [15], the usable proportion of grains refers to the removal of grains with physical damage such as cracks, holes, and discoloration. From each container, 
$100 \mathrm{~g}$ of grains was poured on a tray and sorting was done by removing all damaged grains (perforated, cracks, and discolored) together with chaffs and grain hulls. The usable proportion (or wholesome grains) left after sorting was re-weighed. The usable proportion of grains after storage was then computed using Eq. 2 which has also been used by [4] in a similar study.

$$
\text { Usable proportion (\% weight })=\frac{M_{\mathrm{u}}}{M_{\mathrm{t}}} \times 100 \text {, }
$$

where $M_{\mathrm{u}}=$ mass of usable grains $(\mathrm{g})$ and $M_{\mathrm{t}}=$ total mass of grains $(\mathrm{g})$.

\section{Determination of 1000 grain mass after storage}

From each container, 1000 grains were randomly counted and weighed. As recommended by [16], a small portion between 100 and 1000 grains should be removed from each cleaned sample when assessing weight loss. For each storage system, triplicate experiments were performed.

\section{Determination insect infestation}

As recommended by [16], between 100 and 1000 grains of cowpea are needed when estimating insect attack. In this study, insect infestation was investigated by weighing $100 \mathrm{~g}$ samples from each container. Afterwards, a mesh sieve of diameter $4.80 \mathrm{~mm}$ was used to remove all insects from the stored grains. The number of live cowpea weevils (Callosobruchus maculatus) which fell through the sieve apertures was manually counted. For every system of storage, triplicate experiments were performed.

\section{Data analysis}

Data obtained were analyzed using students' edition of Statistix 9.0 statistical software. Analysis of variance (ANOVA) was performed on the various means to know if differences existed. If significant differences existed, Tukey-Kramer's HSD (Honest Significant Difference) pairwise comparison test was used to determine multiple comparisons. The significance was set at $p$ value less than 0.05 .

\section{Results}

\section{Determination of moisture content of cowpea}

Figure 1 shows the moisture content of the cowpea in the hermetic and non-hermetic systems over the 12 weeks of storage. It was observed that the moisture content in the hermetic containers increased steadily from $11.7 \%$ in week $0-11.9 \%$ by week 12 . However, for the non-hermetically stored grains, the moisture content increased from $11.7 \%$ in week $0-16.5 \%$ in the eighth, and from then it experienced a steady rise till it reached $17.2 \%$ by the twelfth week. Comparing the two storage systems, the non-hermetic system resulted in a significant increase in

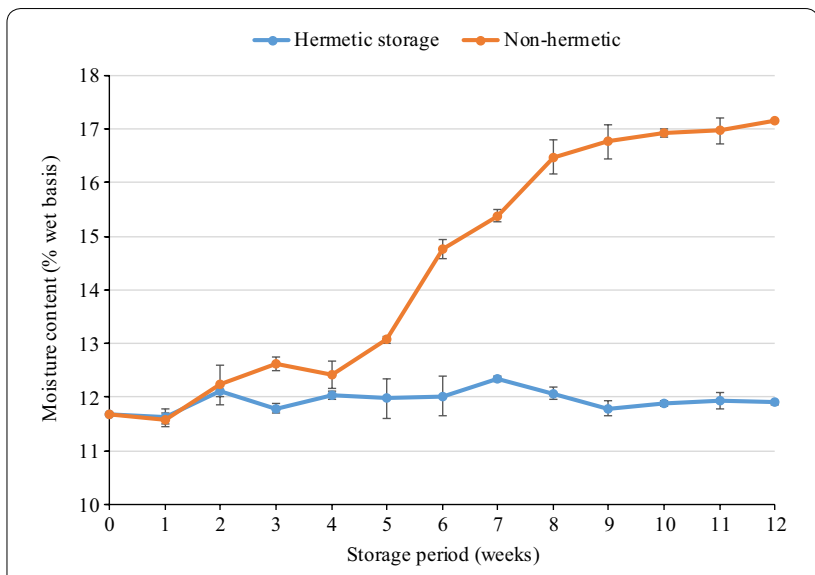

Fig. 1 Moisture content of grains in hermetic and non-hermetic containers at different storage periods. Error bars indicate standard deviation from the mean of triplicate experiments for hermetically and non-hermetically stored grains

moisture content over the 12 weeks of storage compared to the hermetically stored grains $(p<0.05)$.

\section{Determination of insect infestation}

As illustrated in Fig. 2, the insect population in the sealed containers increased from 5 in week $0-10$ per $100 \mathrm{~g}$ of grains in the first week; however, it dropped to approximately 0 from the second week through to the twelfth week. Also, it was evident that the number of live insects increased from 5 in week $0-15$ (live insects $/ 100 \mathrm{~g}$ of grains) in after 1 week of storage. The grains in the nonhermetically stored container observed a continuous increase in the number of live insects till it reached 71 (live insects/100 g of grains) on the twelfth week. Comparing the two storage systems, the non-hermetic system resulted in a significant increase in the number of weevils

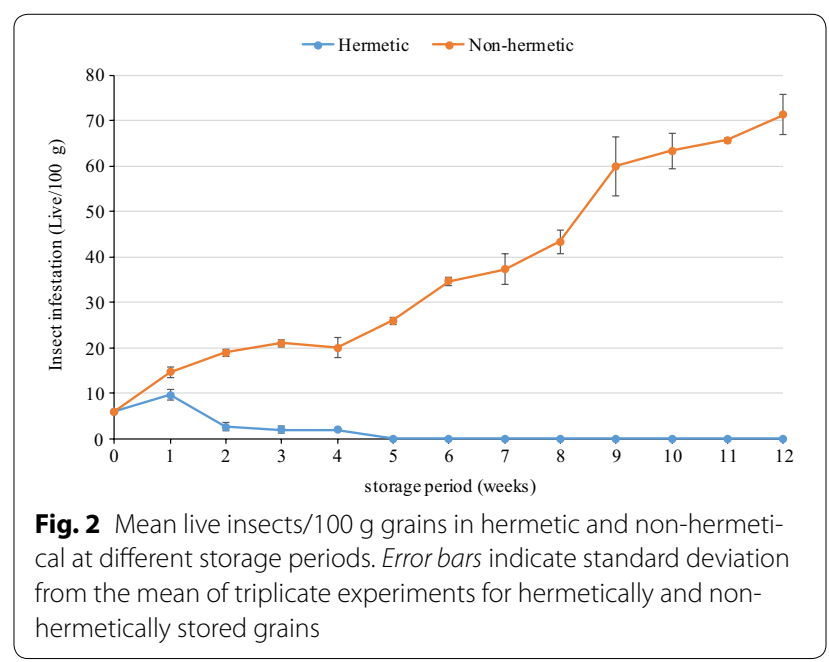


over the twelfth weeks of storage compared to the hermetically stored grains $(p<0.05)$.

\section{Determination of $\mathbf{1 0 0 0}$ grain mass after storage}

From Fig. 3, it can be seen that the mass of grains declined for both hermetic and non-hermetic storage systems, although the decline in mass was highly prevalent in the non-hermetically stored grains. It was observed that the mass of grains reduced from $156.50 \mathrm{~g}$ in week $0-145.21 \mathrm{~g}$ in the non-hermetically stored grains. However, the hermetically stored grains observed a decline from $156.50 \mathrm{~g}$ in week $0-148.95 \mathrm{~g}$. The analysis of variance (ANOVA) performed on the mass of grains showed no significant differences between the two storage systems over the 12 weeks of storage $(p>0.05)$.

\section{Determination of usable proportion}

The initial usable proportion of the cowpea stored was 98.55\% for both hermetic and non-hermetic systems (Fig. 4). There was a decline in the usable proportion of cowpea in both systems over the whole period of storage. The usable proportion of cowpeas in the hermetic containers recorded a gradual decline from $98.55 \%$ in week $0-94.80 \%$ by the twelfth week. In the case of nonhermetically stored grains, although the percentage of the usable (or wholesome) grains in the non-hermetic system only declined from 98.55 to $98.35 \%$ after 1 week of storage as compared to the drop to $98.21 \%$ seen in the hermetic system, the usable proportion of grains in the non-hermetic system dropped sharply from $98.35 \%$ till it reached $85.69 \%$ after 12 weeks of storage. Comparing the two storage systems, the non-hermetic system resulted in a significant decrease in the usable proportion of grains over the 12 weeks of storage compared to the hermetically stored grains $(p<0.05)$.

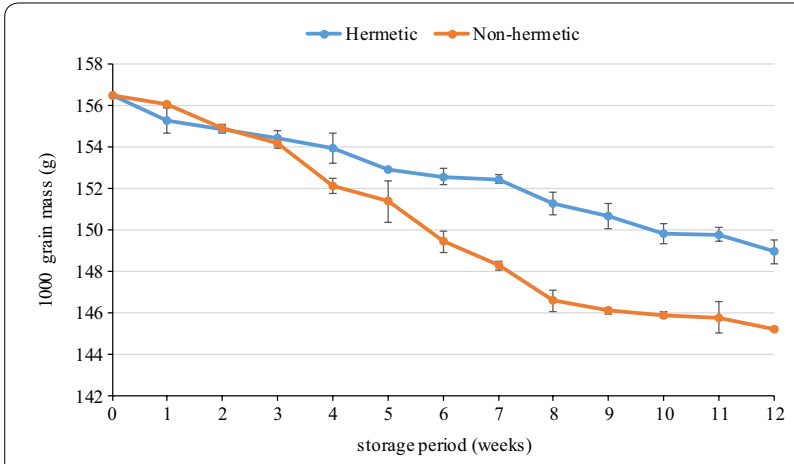

Fig. 3 Mean mass of 1000 grains from hermetic and non-hermetic containers at different storage periods. Error bars indicate standard deviation from the mean of triplicate experiments for hermetically and non-hermetically stored grains

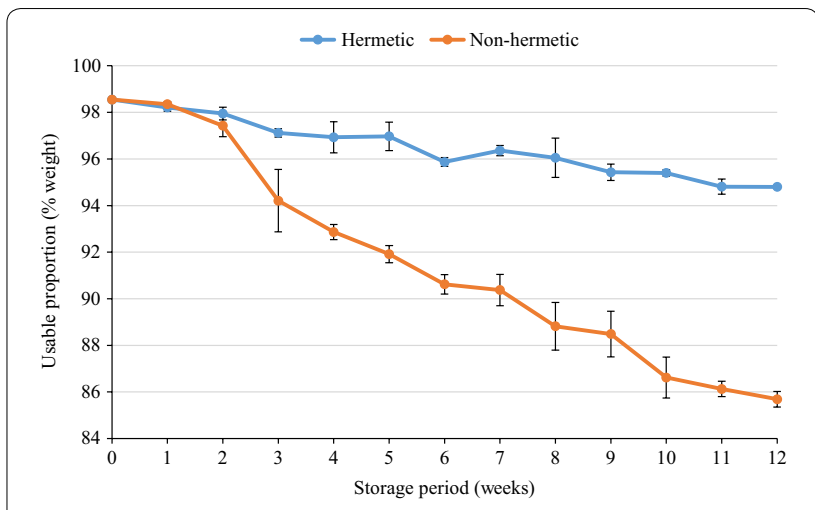

Fig. 4 Mean usable proportion of grains from hermetic and nonhermetic containers at different storage periods. Error bars indicate standard deviation from the mean of triplicate experiments for hermetically and non-hermetically stored grains

\section{Discussion}

\section{Determination of moisture content of cowpea}

From the results presented, the high moisture content observed in the non-hermetic grains compared to the hermetically stored grains was due to the exchange of moisture between the grains and its surrounding since they were left unclosed. The steep rise in moisture content in the non-hermetic containers began from the fifth week up to the eighth week. From the eighth week, a gentle rise in the moisture content of grains was observed. The steady rise in moisture content in the non-hermetically stored grains from the eighth week up to the twelfth week as observed in Fig. 1 was principally due to the dry season (also known as harmattan season) in the country which occurs in January every year, where the relative humidity in the atmosphere decreased from $82 \%$ in December to $78 \%$ in January; therefore, moisture absorption by the grains was minimal. Although the hermetic containers were very efficient in controlling moisture content, there was some slight increase in the moisture $(0.22 \%)$ which could mainly be due to the respiratory activities of insects within the containers or moisture ingress because the caps were not completely airtight. After 12 weeks of storage, the hermetically stored grains recorded final moisture content of $11.90 \%$ which is good enough to prevent formation of molds. This conclusion was made with reference to studies by other researchers which reported that if grains are dried to $14 \%$ moisture or less, minimal or no fungi formation is observed $[9,10$, 17].

\section{Determination of insect infestation}

As presented in the results, the increase in the number of insects observed in the hermetically stored grains after 1 week of storage was principally due to the presence 
of some amount of oxygen which aided in the survival of the insects. However, from this period, the hermetically stored grains resulted in the rapid mortality of the insects. $[9,10,17]$ observed a similar trend where after 4 weeks of storage, the population of cowpea weevils (Callosobruchus maculatus) reduced drastically to zero, and it was concluded that oxygen in the system was consumed and carbon dioxide production increased, which eventually killed the insects. In sharp contrast to the observations made in the hermetically stored grains, there was a continuous rise in the population of live insects in the non-hermetic container. As explained earlier, this was mainly due to the fact that the non-hermetic containers continuously provided the necessary conditions for their rapid growth and development which was also consistent with the study by [10].

\section{Determination of 1000 grain mass after storage}

From the results, although the weight loss in both hermetic and non-hermetic systems was not significantly different at $5 \% p$ value, the hermetic containers were able to slightly stabilize and slow down weight loss. The slight loss in weight observed in the hermetically stored containers could primarily be due to the slight infestation by insects (see Fig. 2). For the non-hermetic system, the rapid loss in weight was mainly due to the fact that the system provided favorable conditions for the insects to live and subsequently bored into the grains. Since the analysis of variance (ANOVA) performed showed no significant difference between the weight loss in the two systems, it could be explained that the simultaneous ingestion by insects and moisture ingress in non-hermetic system might have contributed to the little difference in weight compared to the hermetic system which was not the case of the hermetic system which experienced little moisture ingress and minimal insect infestation. In a similar study, [12] also recorded similar results where the hermetic containers were able to stabilize the weight of grains in the hermetic system and a rapid decline in the weight of grains in the non-hermetic container.

\section{Determination of usable proportion}

In general, the usable proportion of grains in the hermetic containers remained fairly constant as compared to the non-hermetic containers. These changes were mainly due to the fact that the hermetic system operated under the principle of gradual depletion of oxygen and the generation of carbon dioxide through the respiratory activities of insects and the grains $[9,10,12,17]$. The population of insects dropped steadily which, in effect, controlled the destruction of whole grains. The sharp increase in the percentage of unwholesome grains in the non-hermetic system was mainly because no preventive measures were made available to terminate the activities of insects. The environmental conditions surrounding the grains ensured that sufficient oxygen was always available for the insects to comfortably respire and ingest the grains [17].

\section{Conclusions}

The study compared the effect of hermetic and nonhermetic storage systems of storing cowpeas on grain moisture content, infestation by cowpea weevil (Callosobruchus maculatus), weight of cowpeas, and finally usable (or wholesome) proportion of grains after storing grains for 12 weeks. Observations made from the investigations proved that the hermetic storage technology was able to stabilize the moisture content of cowpea stored compared to the non-hermetic system of storage. In addition, the hermetic storage system drastically reduced the number of live insects to a mortality rate of $100 \%$ over the storage period. Although there was no significant difference in weight loss, the hermetic storage system slightly minimized weight loss compared to the non-hermetic system and maintained a high proportion of wholesome grains (usable proportion) compared to the non-hermetic system. The measured parameters in the hermetic and non-hermetic storage techniques clearly depicted that hermetic storage is a preferred option for storing cowpea and could be used replace the use of fumigants and other expensive storage systems. This study recommends that cowpea farmers, middle men, and other retailers will adopt hermetic storage system in order to minimize postharvest losses observed in handling cowpeas. In terms of further studies, it is recommended that efforts should be made to quantify mold infestation and the germination potential of grains stored hermetically.

\section{Authors' contributions}

All authors collaborated to carry out the work presented. The research theme was defined by JOD; the laboratory experiments were carried out by DA; Data analysis and interpretation of results were undertaken by NB, JOD, and DA; DA and NB wrote the paper. All authors read and approved the final manuscript.

\section{Author details \\ ${ }^{1}$ Department of Agricultural and Bio-Systems Engineering, Makerere Univer- sity, P.O. Box 7062, Kampala, Uganda. ${ }^{2}$ Department of Agricultural Engineer- ing, Kwame Nkrumah University of Science and Technology, PMB Kumasi, Kumasi, Ghana.}

\section{Acknowledgements}

We appreciate the effort put in by the Animal Science Department of Kwame Nkrumah University of Science and Technology in Ghana where all laboratory experiments were undertaken. Sincere thanks also goes to the Department of Agricultural Engineering for all the support provided during this project.

\section{Competing interests}

The scientific responsibility is accredited to the authors. Hence, the authors declare that they have no competing interests. 


\section{Availability of data and materials}

The dataset supporting the conclusions of this article is available in the FigShare repository (https://dx.doi.org/10.6084/m9.figshare.4479431).

\section{Funding}

All funds used in this work were direct contributions from the authors.

Received: 26 September 2016 Accepted: 30 January 2017

Published online: 08 May 2017

\section{References}

1. Baributsa D, Lowenberg-DeBoer J, Murdock L, Moussa B. Profitable chemical-free cowpea storage technology for smallholder farmers in Africa: opportunities and challenges. In: 10th international working conference on stored product protection. 2010. p. 1046-52.

2. National Research Council. Crop experts embrace legume prized for protein and resilience to hot, dry climates. Natl Res Counc Conf. 2009. http:// www.sciencedaily.com/releases/2010/09/100927105157.com.

3. Seck D, Lognay G, Haubruge E, Marlier M, Gaspar C. Alternative protection of cowpea seeds against Callosobruchus maculatus (F.) (Coleoptera: Bruchidae) using hermetic storage alone or in combination with Boscia senegalensis (Pers.) Lam ex Poir. J Stored Prod Res. 1996;32:39-44.

4. Nyamadi P, Maphosa M. Evaluating the effects of indigenous cowpea weevil Callosobruchus rhodesianus management methods on stored cowpea. Int J Agric Crop Sci. 2013;5:2761-7.

5. Udo IO, Harry Gl. Effect of groundnut oil in protecting stored cowpea (Vigna unguiculata) from attack by cowpea weevil (Callosobruchus maculatus). J Biol Agric Healthc. 2013;3:89-93.

6. Affognon $\mathrm{H}$, Mutungi C, Sanginga P, Borgemeister C. Unpacking postharvest losses in sub-Saharan Africa: a meta-analysis. World Dev. 2015;66:49_ 68. doi:10.1016/j.worlddev.2014.08.002.

7. Keatts A. Smallholder grain storage in sub-Saharan Africa. Fintrac Top Pap. 2016;3:1-8.
8. De Bruin T, Villlers P, Navarro S. Worldwide developments in ultra hermetic $^{\mathrm{TM}}$ storage and solar drying technologies. In: 11th international working conference on stored product protection. 2010. p. 12-17.

9. Quezada MY, Moreno J, Vazquez ME, Mendoza M, Mendez-Albores A, Moreno-Martinez E. Hermetic storage system preventing the proliferation of Prostephanus truncatus horn and storage fungi in maize with different moisture contents. Postharvest Biol Technol. 2006;39:321-6.

10. Bern CJ, Yakubu A, Brumm TJ, Rosentrater KA. Hermetic storage systems for maize stored on subsistence farms. Am Soc Agric Biol Eng Annu Int Meet. 2013;1:802-9. http://www.scopus.com/inward/record. url?eid=2-s2.0-84881646628\&partnerlD=tZOtx3y1.

11. Tobergte DR, Curtis S. Evaluating the effectiveness of alternative extension methods: triple-bag storage of cowpeas by small-scale farmers in West Africa. J Chem Inf Model. 2013;53:1689-99.

12. Asawalam EF, Anaeto CG. Laboratory evaluation of five botanicals as protectants against cowpea bruchid Callosobruchus maculatus F. (Coleoptera : Bruchidae) on stored cowpea. Adv Med Plant Res. 2014;2:41-6.

13. Brooker DB, Bakker-Arkema FW, Hall CW. Drying and storage of grains and oilseeds. Berlin: Springer; 1992.

14. Karimu D. Comparative study of cowpea storage in different storage structures. Kumasi: Kwame Nkrumah University of Science and Technology; 2010. http://ir.knust.edu.gh/bitstream/123456789/729/1/DRAMANIKARIMU.pdf.

15. De Groote H, Kimenju SC, Likhayo P, Kanampiu F, Tefera T, Hellin J. Effectiveness of hermetic systems in controlling maize storage pests in Kenya. J Stored Prod Res. 2013;53:27-36. doi:10.1016/j.jspr.2013.01.001.

16. Adams JM, Harman GW. Postharvest grain loss assessment methods. In: Harris KL, Lindbald CJ, editors. The American Association of cereal chemists; 1978. http://pdf.usaid.gov/pdf_docs/PNAAG842.pdf.

17. Bbosa D, Brumm TJ, Bern CJ, Rosentrater KA. Evaluation of hermetic maize storage for smallholder farmers. Montreal: ASABE CSBE/SCGAB Annual Meeting; 2014. p. 13.

\section{Submit your manuscript to a SpringerOpen ${ }^{\circ}$ journal and benefit from:}

- Convenient online submission

- Rigorous peer review

- Immediate publication on acceptance

- Open access: articles freely available online

- High visibility within the field

- Retaining the copyright to your article 